\title{
Erosion/Redeposition Analysis of Lithium-Based Liquid Surface Divertors ${ }^{1}$
}

\author{
J. N. Brooks \\ Argonne National Laboratory \\ T. Rognlien \\ Lawrence Livermore National Laboratory \\ D. N. Ruzic \& J. P. Allain \\ University of Illinois \\ The submitted manuscript has been created \\ by the University of Chicago as Operator of \\ Argonne National Laboratory ("Argonne") \\ under Contract No. W-31-109-ENG-38 with \\ the U.S. Department of Energy. The U.S. \\ Government retains for itself, and others act- \\ ing on its behalf, a paid-up, nonexclusive \\ irrevocable worldwide license in said article \\ to reproduce, prepare derivative works, dis- \\ tribute copies to the public, and perform pub- \\ licly and display publicly, by or on behalf of \\ the Government.

\section{$14^{\text {th }}$ International Conference Plasma Surface Interactions}

May 22-26, 2000

Rosenheim, Germany

'Work supported by the Office of Fusion Energy Sciences

U.S. Department of Energy Under Contract W-31-109-Eng-38 


\section{DISCLAIMER}

This report was prepared as an account of work sponsored by an agency of the United States Government. Neither the United States Government nor any agency thereof, nor any of their employees, make any warranty, express or implied, or assumes any legal liability or responsibility for the accuracy, completeness, or usefulness of any information, apparatus, product, or process disclosed, or represents that its use would not infringe privately owned rights. Reference herein to any specific commercial product, process, or service by trade name, trademark, manufacturer, or otherwise does not necessarily constitute or imply its endorsement, recommendation, or favoring by the United States Government or any agency thereof. The views and opinions of authors expressed herein do not necessarily state or reflect those of the United States Government or any agency thereof. 


\section{DISCLAIMER}

Portions of this document may be illegible in electronic image products. Images are produced from the best available original document. 


\title{
Erosion/Redeposition Analysis of Lithium-Based Liquid Surface Divertors ${ }^{1}$
}

\author{
J. N. Brooks, T. Rognlien ${ }^{a}$, D.N. Ruzic ${ }^{b}$, J.P. Allain ${ }^{b}$ \\ Argonne National Laboratory, 9700 S. Cass Ave., Argonne, IL 60439, USA \\ a Lawrence Livermore National Laboratory, Livermore, CA, USA \\ buniversity of Illinois, Urbana, IL, USA
}

\begin{abstract}
An erosion/redeposition analysis was performed for three candidate tokamak fusion reactor liquid divertor surfaces-lithium, tin-lithium $\left(\mathrm{Sn}_{80} \mathrm{Li}_{20}\right)$, and flibe $\left(\mathrm{LiF}+\mathrm{BeF}_{2}\right.$ salt $)$. The analysis uses coupled edge-plasma, impurity-transport, and sputtering codes (UEDGE/WBC/VFTRIM), and available sputtering data. A pure-lithium surface strongly absorbs impinging D-T ions-this results in a high temperature, low density, $\left(\sim 200 \mathrm{eV}, \sim 1 \times 10^{19} \mathrm{~m}^{-3}\right)$ low-recycle plasma edge regime. Lithium appears to perform well in this regime. Although overall sputtering is high selfsputtering is finite. Most ( $95 \%)$ of the sputtered lithium is confined to the near-surface region and redeposited on the divertor with the remainder $(\sim 5 \%)$ also being redeposited after transport in the scrape off layer. Lithium core plasma contamination potential is low $\left(\sim 10^{-4} \mathrm{Li} / \mathrm{D}-\mathrm{T}\right)$. Tinlithium and flibe would likely operate in a high-recycle regime (e.g. $30 \mathrm{eV}, 3 \times 10^{20} \mathrm{~m}^{-3}$ ). Erosion/redeposition performance of these materials is also good, with finite self-sputtering and negligible core plasma contamination predicted, but with some potential for changing surface composition due to different constituent element redeposition distances.
\end{abstract}

\section{Introduction}

\footnotetext{
' Work supported by the US Department of Energy, Office of Fusion Energy.
} 
Flowing liquid surfaces for fusion reactors mitigate sputtering and disruption lifetime concerns, but there are remaining concerns about self-sputtering runaway, plasma contamination, tritium codeposition in far-transported solidifying material, and overall edge-plasma/surface compatibility. As part of the US ALPS project [1] we are assessing these issues for several materials. In this study we report on initial analysis for three lithium based liquids. This analysis covers generic type plasma-surface interaction issues with follow-up studies using detailed engineering designs expected to follow.

\section{Pure lithium surface}

\subsection{Method}

The UEDGE fluid plasma code [2] was used to compute an edge plasma solution for an ITERtype reactor with a vertical divertor [3] flowing liquid lithium surface and strongly absorbing D-T boundary conditions. The UEDGE calculation was done for the outer half of the scrape off layer (sol) with $100 \mathrm{MW}$ power input from the core, core/sol boundary D-T density of $4 \times 10^{19} \mathrm{~m}^{-3}$, and particle and energy diffusion coefficients of $\mathrm{D}=0.33 \mathrm{~m}^{2} / \mathrm{s}, \chi_{\mathrm{e}}=\chi_{\mathrm{i}}=0.5 \mathrm{~m}^{2} / \mathrm{s}$. We use A D-T ion reflection coefficient at the lithium divertor $R=0.5$, representing an initial rough estimate based on high hydrogen solubility in lithium and high removal capacity due to constant replenishment of the surface by flow. (The plasma solution is not strongly dependent on $\mathrm{R}$ in the range $0.25 \leq \mathrm{R} \leq 1.0$ ).

Next, the WBC kinetic impurity transport code [4] was run using the UEDGE plasma solution, with angular and energy dependent $\mathrm{D}^{+}$and $\mathrm{Li}^{+}$on $\mathrm{D}$-saturated liquid Li sputtering coefficients, 
and sputtered velocity distributions, from VFTRIM code [5] calculations calibrated to available data [6]. (For this study, $\mathrm{T}^{+}$sputtering of pure lithium was taken equal to $\mathrm{D}^{+}$sputtering). We use a two-layer ( $\mathrm{Li}, \mathrm{D}$-saturated $\mathrm{Li}$ ) smooth-surface (fractal dimension $=2.00$ ) model, with empirically adjusted binding and bond energies. Lithium atoms were launched in WBC with an energy distribution based on a binding energy of $1.1 \mathrm{eV}$, as best fits the data of Ref. [6], and also well matches PISCES data [7]. Also used for the lithium analysis are ADAS [8] densitydependent collisional radiative electron impact ionization rate coefficients. (Other parameters include magnetic field $B=5 \mathrm{~T}, 33^{\circ}$ poloidal angle, $1.5^{\circ}$ total angle).

WBC computed the self-consistent, near-surface $(0-5 \mathrm{~cm}$ from the plate) transport of D-T sputtered and self-sputtered lithium. The WBC-computed lithium flux escaping the near-surface region was then used as a boundary condition for a further run in UEDGE, to compute lithium transport over the whole sol.

\subsection{Results}

The reference UEDGE plasma solution is shown over the sol in Figure 1 and at the $\sim 40 \mathrm{~cm}$ wide divertor plate in Figure 2. Peak electron temperature at the plate is of the order of $200 \mathrm{eV}-\mathrm{in}$ striking contrast to much colder high-recycle regimes. The peak heat flux to the divertor for this and similar cases (with field angle and other variations examined) is in the range of $\sim 10 \mathrm{MW} / \mathrm{m}^{2}$ which is tolerable. As shown in Figure 1 the density and temperature profiles in the entire sol are fairly constant along poloidal field lines, and thus the high temperature/low density extends upwards to the sol/edge plasma boundary. This type of plasma solution may help the overall 
fusion reactor design (such as reducing the required RF current drive power due to lowered edge density).

Figure 3 shows IIAX experimental data [6] and VFTRIM-3D simulations for $\mathrm{D}^{+}$and $\mathrm{Li}^{+}$ bombardment of D-saturated $\mathrm{Li}$ at $45^{\circ}$ incidence. The VFTRIM-3D results are a reasonably good match to the data at the indicated energies. In addition to Li atom sputtering, both data and code show a roughly equal rate of charged particle, i.e., Li+ sputtering. However, due to $100 \%$ immediate expected redeposition of sputtered $\mathrm{Li}+$ by gyromotion and sheath acceleration, only neutral sputtered lithium needs to be tracked, for the present purposes.

The WBC/UEDGE lithium erosion/redeposition results, summarized in Figures 4-5 and Table 1, are favorable. In spite of high redeposited $\mathrm{Li}^{+}$energies and generally oblique incidence, selfsputtering is limited, comprising some $25 \%$ of the total. Of the total sputtered lithium current, $\sim 95 \%$ is locally redeposited via near-surface impurity/plasma transport processes, $\sim 5 \%$ leaves the near-surface region but returns to be redeposited after transport in the sol, and $\sim 0.2 \%$ enters the private flux region or hits the first wall. Lithium is thus mostly confined to the near surface region. A liquid surface has, of course, zero net erosion on the time scale of the liquid flow, however, gross and instantaneous (i.e. before liquid flow) net erosion rates are shown (Fig. 4) for comparison to different materials and previous studies. These rates are high, but due to the high local confinement, of apparently limited significance. 
Figure 5 shows the combined WBC/UEDGE computed lithium density along one poloidal field line in the sol plasma. As mentioned, the codes are coupled here at $5 \mathrm{~cm}$ perpendicular to the plate or $8 \mathrm{~cm}$ along the poloidal field line. The trends seen in Figure 4 are similar for other field lines. The lithium concentration is about $0.2 \mathrm{Li} / \mathrm{D}-\mathrm{T}$ near the surface but falls off very rapidly away from the plate reaching a very low value at the top of the tokamak and along the entire edge/sol boundary. This implies low core plasma contamination by sputtered lithium.

An additional UEDGE/WBC run (not shown) made with a. lower density boundary condition-possibly needed to mitigate D-T refueling concerns-shows similar acceptable low sputtered lithium transport to the core but significantly higher transport to the private flux region. Such higher transport might require keeping all surface temperatures high enough to prevent tritium from codepositing in solidifying lithium regions-this should not be difficult in view of the low lithium melting point $\left(181^{\circ} \mathrm{C}\right)$.

\section{Flibe and Tin-Lithium}

\subsection{Method}

These materials, even though containing lithium, are not expected to significantly pump D-T, due to very low hydrogen solubility. They will typically operate in a "conventional" high recycle regime with $\mathrm{R}$ close to unity. For these materials, at present, we used a simpler plasma model in WBC, namely a uniform plasma with typical high recycle plasma parameters of $T_{e}=30 \mathrm{eV}, \mathrm{N}_{e}=$ $3 \times 10^{20} \mathrm{~m}^{-3}$. The complete sputtering coefficient matrix for flibe, i.e. with all partial yields of $\mathrm{F}$, $\mathrm{Be}, \mathrm{Li}$, for incident bombardment by for $\mathrm{D}^{+}, \mathrm{T}^{+}, \mathrm{Li}^{+}, \mathrm{Be}^{+}$, and $\mathrm{F}^{+}$, was computed with VFTRIM- 
$3 \mathrm{D}$ for molten salt flibe. A bond energy of $6.0 \mathrm{eV}$ was used for both $\mathrm{LiF}$ and $\mathrm{BeF}_{2}[9,10]$. This is justified based on the chemical state of molten salt flibe as consisting of LiF and BeF2 components. The analogous sputtering matrix for $\mathrm{Sn}_{80} \mathrm{Li}_{20}$ was supplied from TRYDIN (selfsputtering) and TRIM.SP (D-T sputtering) calculations [11]. Tin-lithium is assumed to be nonsegregated, i.e. with no Li overlayer, such non-segregating condition expected at high $(>\mathrm{xxxC})$ surface temperatures [11].

ADAS ionization rate coefficients are used for $\mathrm{Li}$ and $\mathrm{Sn}$, other rates used are discussed in [4]. We computed the near-surface transport of all sputtered elements of the respective materials, with self-consistent sputtering based on the $\mathrm{D}, \mathrm{T}$ and self-sputtering angular and energy dependent sputter yield matrices, and the redeposited ion velocities.

\subsection{Results}

Finite self-sputtering is predicted for both materials, with very high local redeposition. For flibe, the highest average sputter yield observed is the F-yielding-F yield of $\sim 0.4-$ well short of the necessary-condition value of $\sim 1.0$ for self-sputter runaway. For tin-lithium, the average $\mathrm{Li}$ yielding-Li yield is $\sim 0.75$, due in part to a high reflection of lithium from the tin component, but this is also safely below unity. Figures 6-7 shows the respective sputtered ion densities near the divertor surface. These are all low in relation to the D-T density $\left(3 \times 10^{20} \mathrm{~m}^{-3}\right)$ and fall off rapidly away from the surface. 
Table 1 summarizes various redeposition parameters for the flibe and tin-lithium components, and also as mentioned previously, for pure lithium. The incident ion angle and energy parameters should, hopefully, be useful in guiding parameter choices for sputtering experiments. For flibe and tin-lithium, mean-free paths are all short-due in large part to the high electron density for the high recycle plasma . After ionization, subsequent strong collisional friction with the incoming plasma - and particularly for $\mathrm{Sn}$ and $\mathrm{Li}$, sheath field acceleration-gives rise to the high local redeposition. Although short, there are non-trivial differences in mean free paths and redeposition distances for the constituent elements of the two multi-materials, particularly for flibe, e.g. fluorine travels poloidally about four times as far as lithium. These differences are due generally to differences in mass and ionization cross sections. This would not matter for a completely uniform plasma but could affect surface composition for a plasma with variations on the scale of the redeposition distances, i.e. order of $1 \mathrm{~cm}$. The effect, if any, on flowing-liquid surface composition, sputtering properties etc. will need evaluation.

For both flibe and tin-lithium, essentially zero core plasma contamination by sputtering is predicted, for this simplified-model plasma case. There is also negligible transport to the first wall/private flux area. Full profile plasma effects might be somewhat different.

\section{Discussion and conclusions}

This study has examined several key plasma surface interaction issues for three candidate liquid divertor surfaces. For a hydrogen absorbing pure lithium surface, plasma sol temperatures are an order of magnitude higher than the usually studied solid-material regimes. This may have 
significant implications for a fusion reactor over and above effects for the divertor itself-an issue being studied for the ALPS project. Lithium sputtering rates are high, but the sputtered lithium is mostly confined to a region close to the divertor surface with resulting low core plasma contamination. The high confinement is due to a combination of high electron-impact ionization rate coefficients, low binding energy/sputtered-velocity, and reasonably high impurity/plasma collision rates. Based on code predictions for redeposited lithium ion energies, and the oblique but not extremely so incident angles, and on available self-sputtering data, we predict that lithium self-sputtering is well short of runaway. Also helping in this regard is the high hydrogen isotope content in the lithium surface which reduces self-sputtering, and the high sputtered ion fraction. The potential for tritium codeposition in lithium redeposited and solidifying in regions far from the main divertor heat deposition area, i.e. first wall and private flux area, also appears to be low, but needs further evaluation for lower density/higher temperature plasma regimes. Other critical psi issues not examined here but needing analysis for pure lithium are: (1) effect of high tritium removal rates on plasma refueling requirements, and (2) helium removal by trapping in the lithium.

For flibe and tin-lithium we computed sputtering and transport of each constituent element including the resulting self-sputtering, for a typical high recycle fusion edge plasma with binary collision type code-predicted sputtering coefficients. As with pure lithium, the erosion results show high confinement of impurities in the near-surface region, with low potential for core plasma contamination and no runaway self-sputtering. These results are encouraging but more work is needed on, for instance, full plasma profile effects, performance for different plasma edge 
temperatures, and effects of erosion/redeposition-caused varying surface composition. Sputtering data is also needed for the multi-component materials. 


\section{References}

1. R.F. Mattas et al., "ALPS-Advanced Limiter-divertor Plasma-facing Systems", Fusion Eng. Des. (to be published).

2. UEDGE

3.. K.J. Dietz et al., Fusion Eng. Design 27(1995)96.

4. J.N. Brooks, Phys. Fluids 8(1990)1858.

5. D.N. Ruzic, Nucl. Instrum. methods D47(1990)3607.

6. J.P. Allain, D.N. Ruzic, J. Nucl. Mater. (these proceedings).

7. The Originating Developer of ADAS is the JET Joint Undertaking.

8. R. Doerner et al., J. Nucl. Mater. (these proceedings).

9. D.J. Cubicciotti, J. Phys. Chem., 71(1967)3066.

10. M. Farber, R.D. Srisvastava, J. Chem. Soc. Faraday Trans. 1,70(1974)1851.

11.. R. Bastasz, SNL, W. Eckstein IPP/Garching, pers. comm. (2000). 


\section{Figure Captions}

1. Electron temperature profiles in the scrape off layer for the UEDGE plasma solution with lowrecycle lithium divertor.

2. Plasma density and temperature profiles at the lithium divertor plate.

3. Sputtering data [6] and VFTRIM-3D code calculations for oblique incidence $\mathrm{D}^{+}$and $\mathrm{Li}^{+}$on $\mathrm{D}$ saturated lithium.

4. Gross and instantaneous (before liquid flow) net erosion rates from the WBC analysis of the liquid lithium divertor.

5. WBC/UEDGE computed lithium density along a poloidal field line midway in the sol $(\sim 15 \mathrm{~cm}$ from the separatrix on the plate).

6. Sputtered ion densities near the divertor plate for a flibe divertor.

7. Sputtered ion densities near the divertor plate for a tin-lithium divertor. 


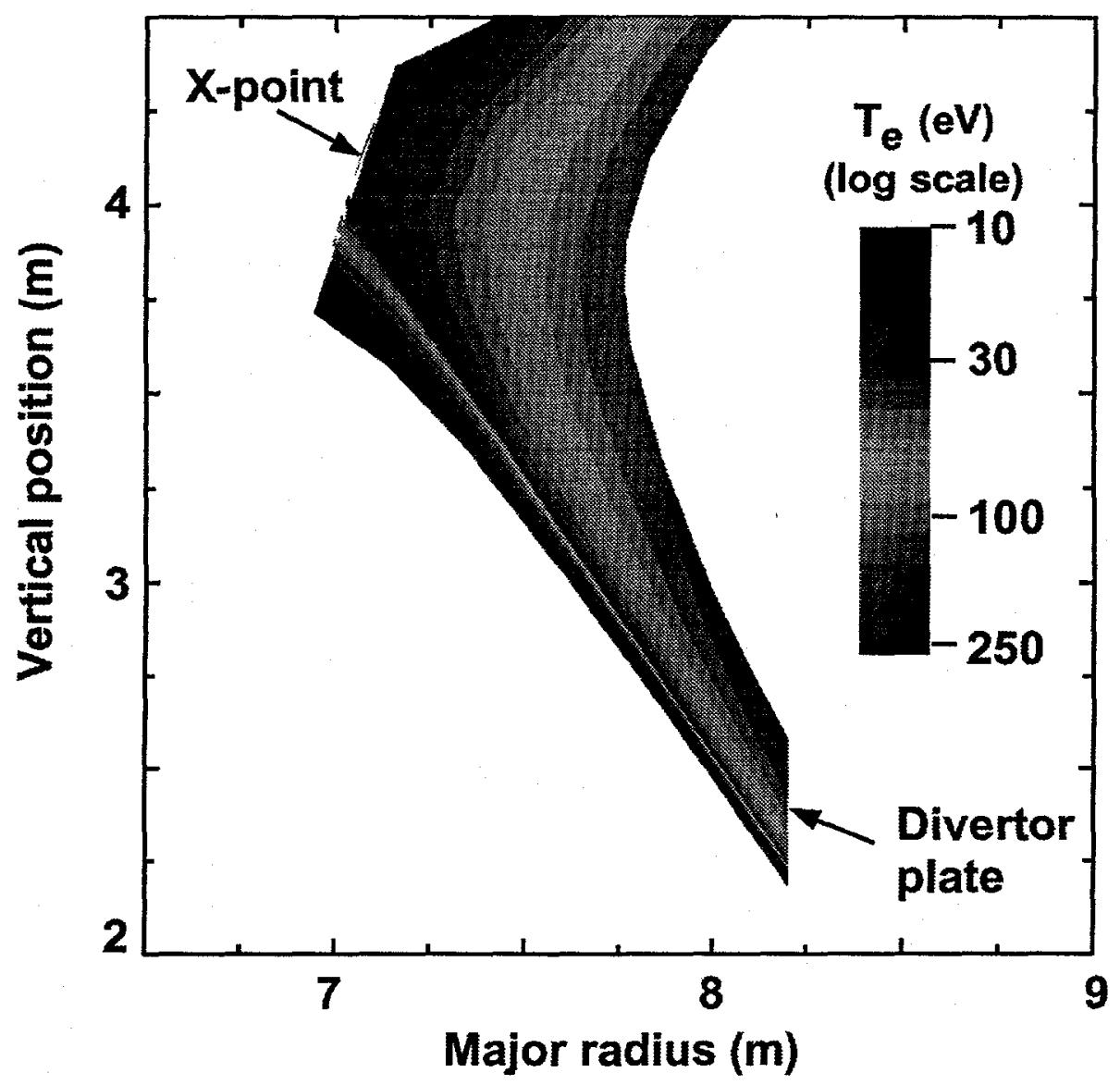




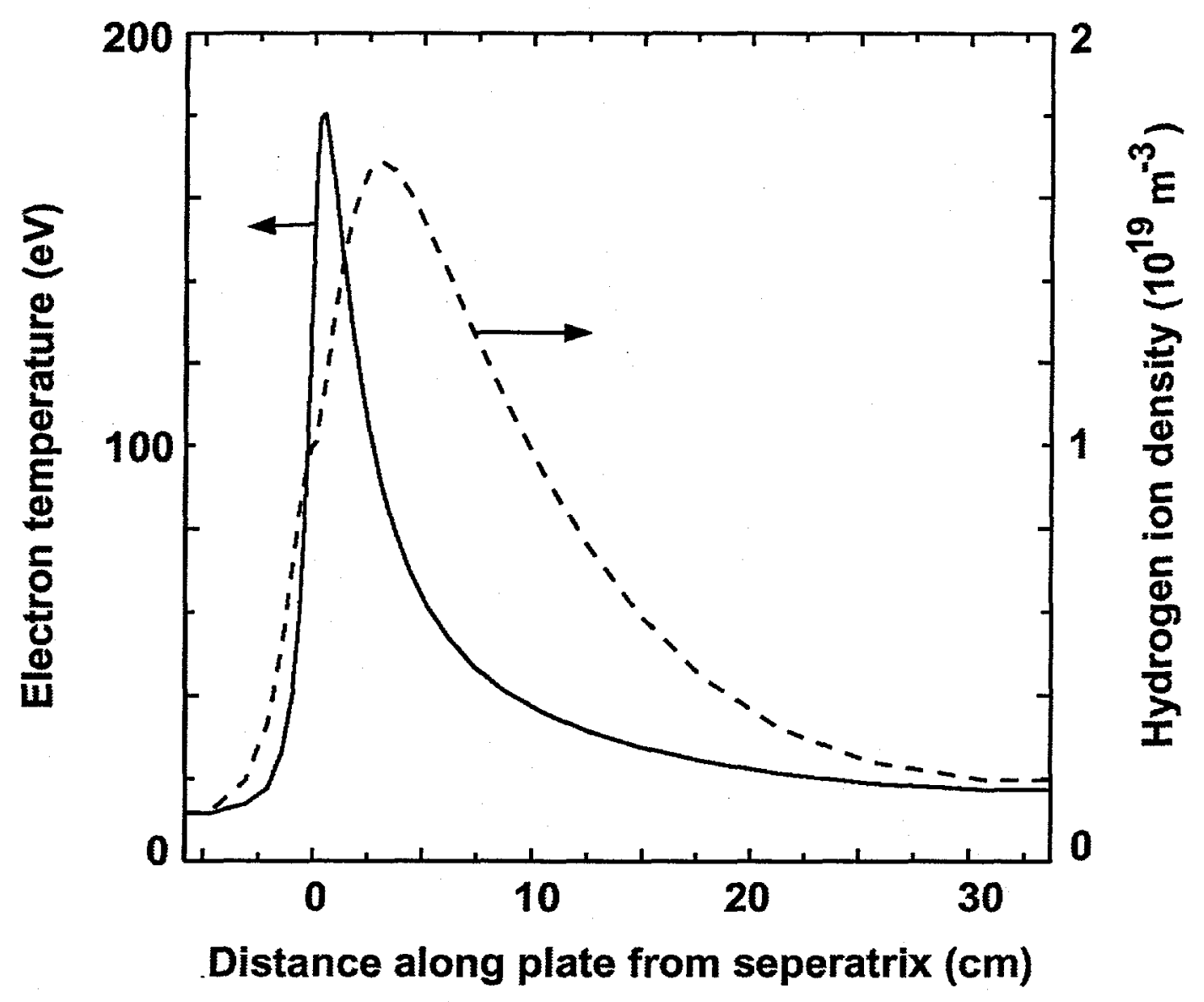




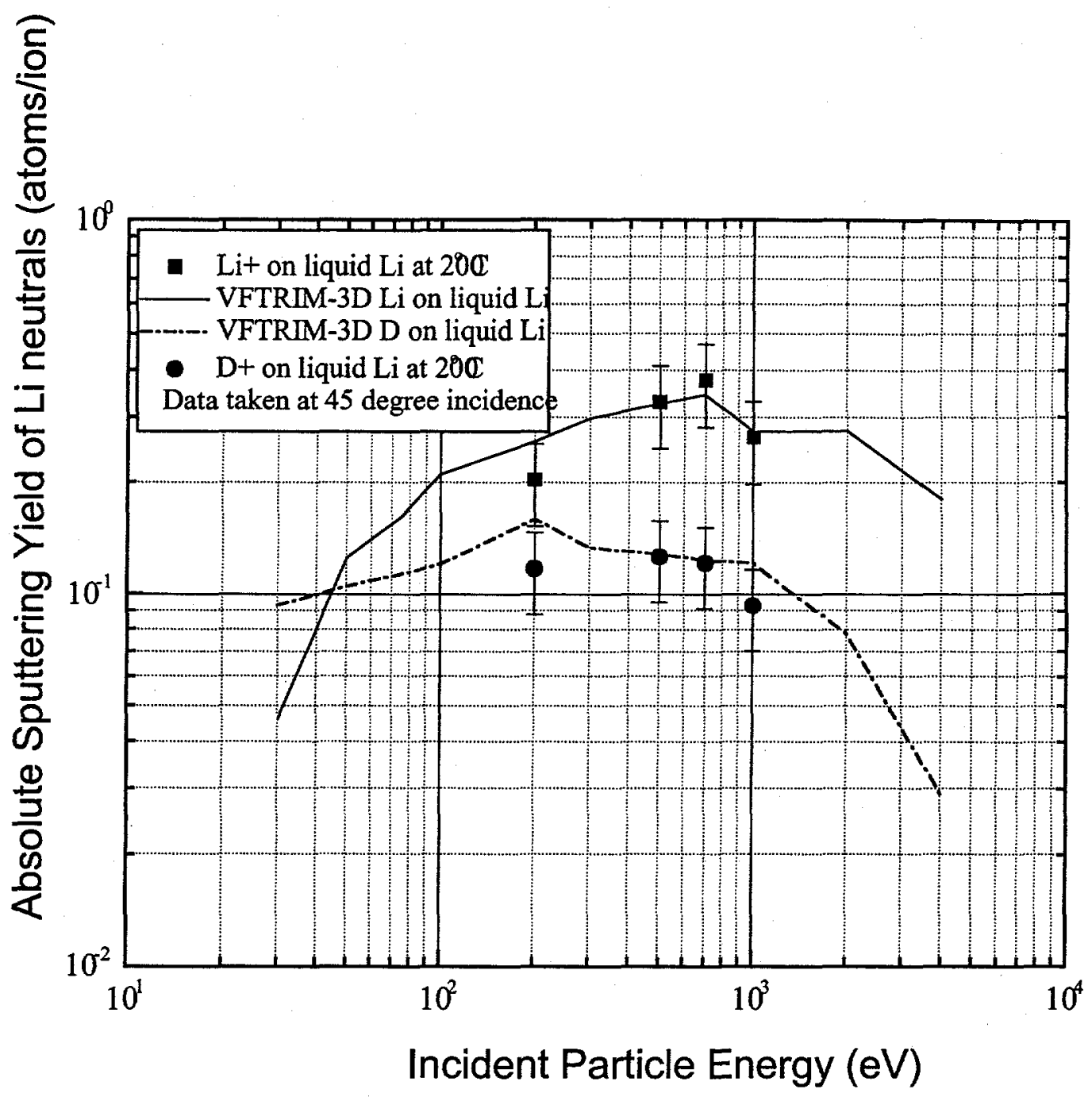




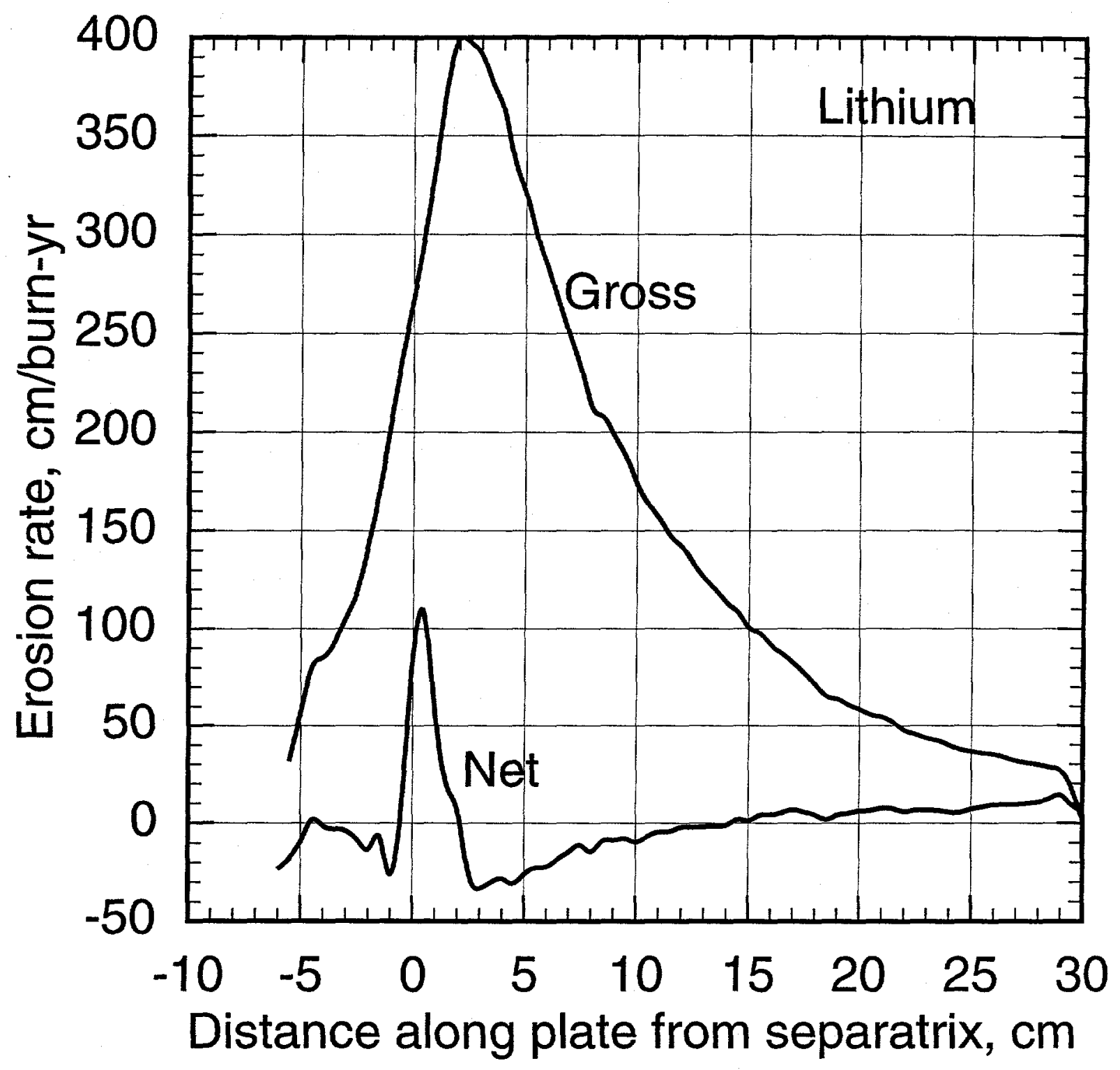




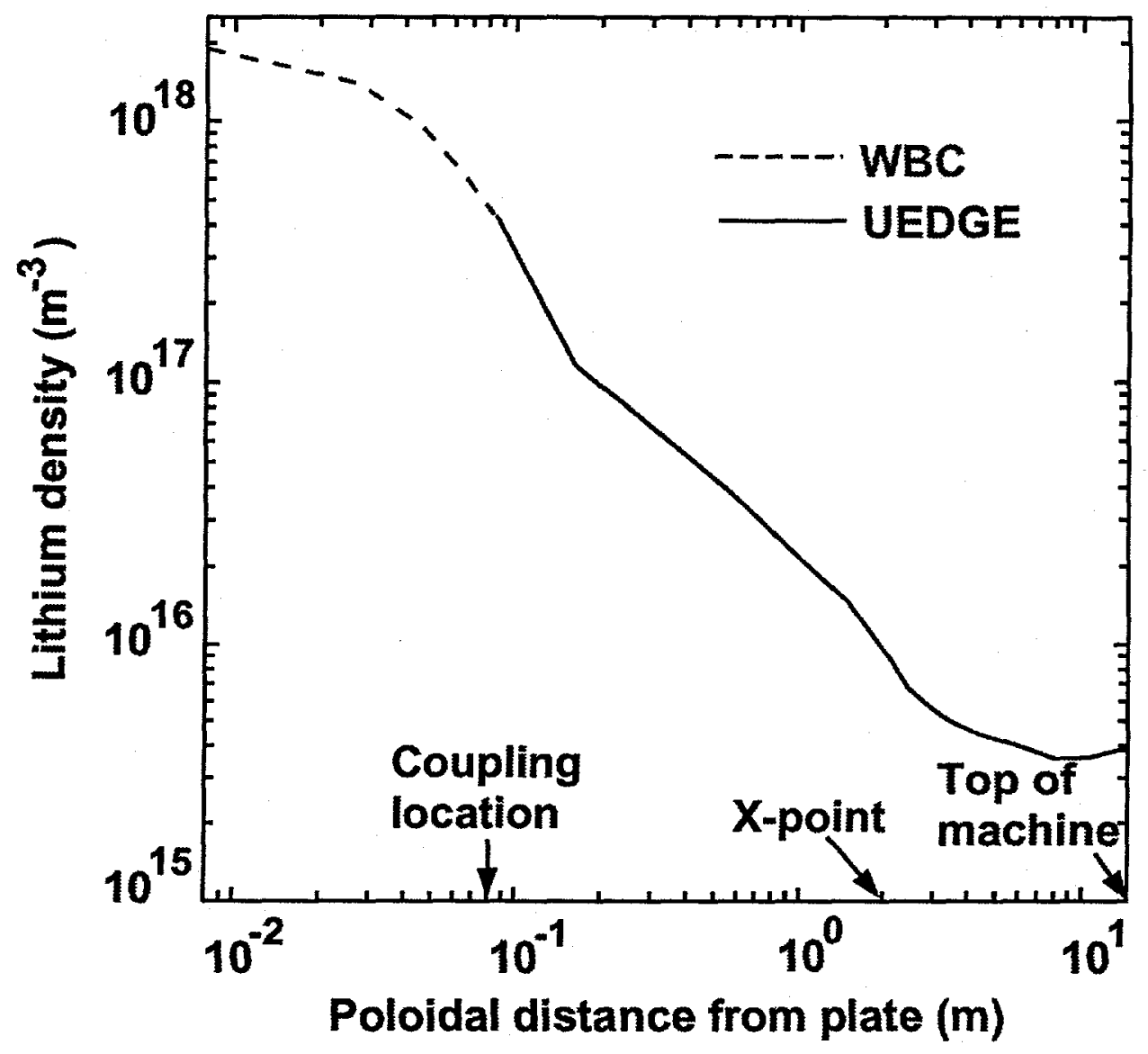




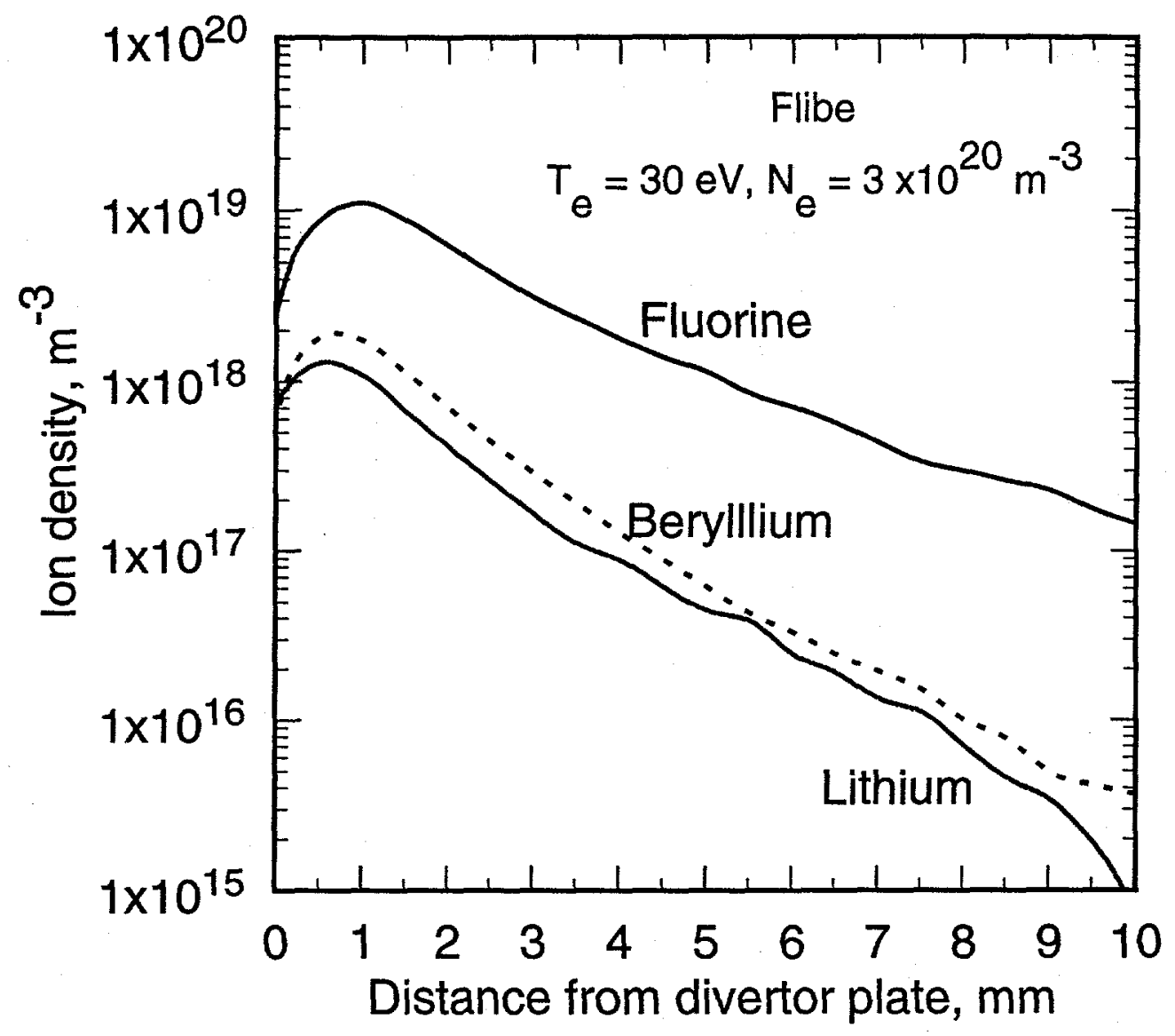




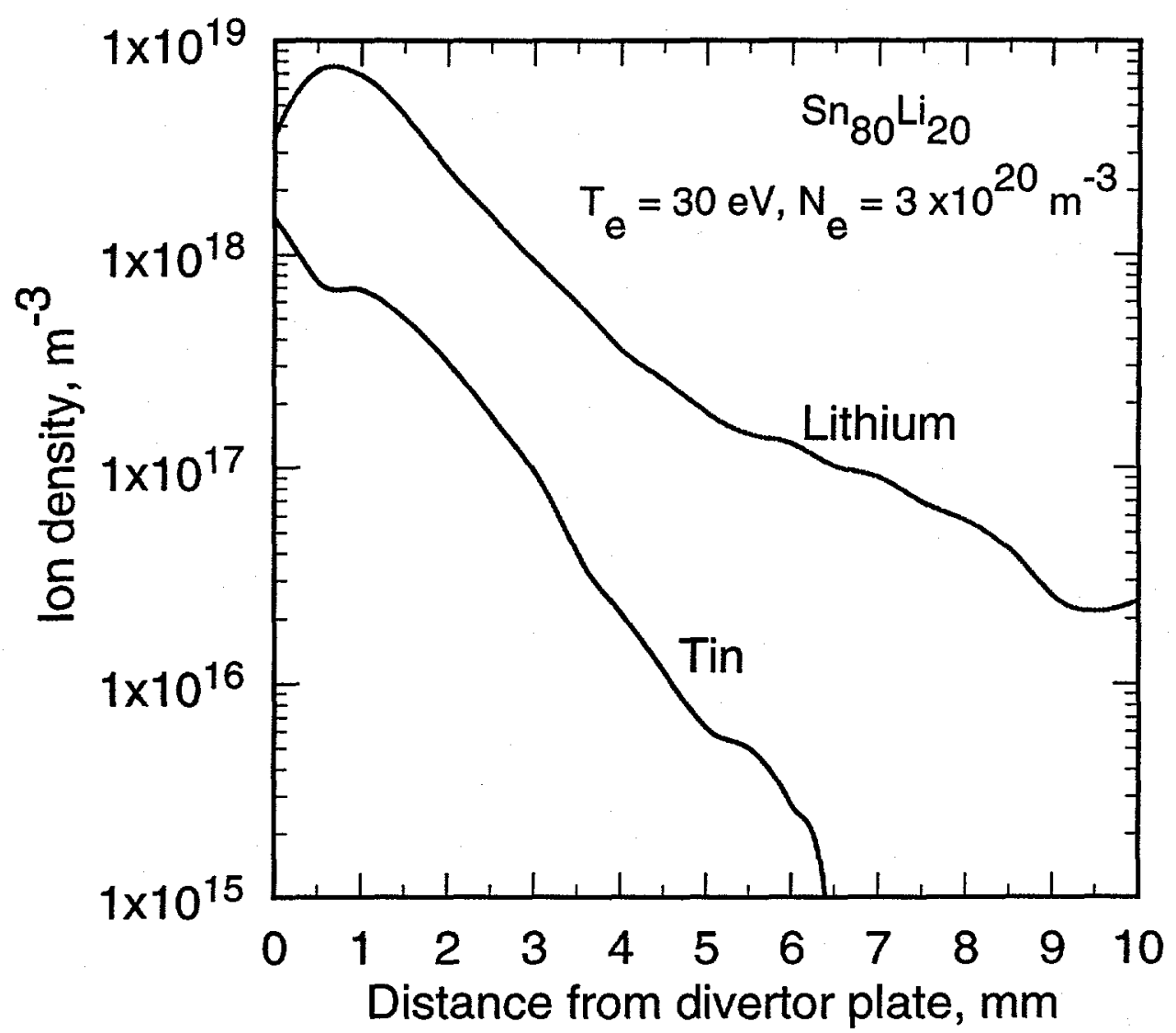


Table 1 Selected erosion/redeposition parameters from WBC analysis of three liquid divertor surfaces.

\begin{tabular}{|c|c|c|c|c|c|c|}
\hline \multirow[t]{2}{*}{ Parameter } & \multirow{2}{*}{$\begin{array}{l}\text { LITHIUM } \\
\text { (pure) }\end{array}$} & \multicolumn{2}{|c|}{ TIN-LITHIUM } & \multicolumn{3}{|c|}{ FLIBE } \\
\hline & & $\mathrm{Li}$ & Sn & $\mathrm{Li}$ & $\mathrm{Be}$ & $\mathrm{F}$ \\
\hline $\begin{array}{l}\text { Plasma conditions at divertor; } \\
\mathrm{Te}(\mathrm{eV}) / \mathrm{Ne}\left(10^{-3} \mathrm{~m}^{-3}\right)\end{array}$ & $\begin{array}{l}\text { variable; } \\
185 / 0.1 \text { at } \\
\text { separatrix }\end{array}$ & \multicolumn{2}{|c|}{$30 / 3$} & \multicolumn{3}{|c|}{$30 / 3$} \\
\hline Binding energy, eV & 1.12 & 2.40 & 2.40 & 7.49 & 7.49 & 7.49 \\
\hline Neutral ionization distance, $\mathrm{mm}$ & 4.6 & $0.29^{\mathrm{c}}$ & 0.15 & 0.30 & 0.86 & 1.4 \\
\hline Charge state & 1.1 & 1.0 & 1.5 & 1.0 & 1.5 & 2.0 \\
\hline Transit time, $\mu \mathrm{s}$ & 15 & 0.33 & 0.17 & 0.24 & 0.85 & 1.6 \\
\hline Elevation angle, ${ }^{\circ}$ & 53 & 32 & 15 & 30 & 42 & 42 \\
\hline Energy, eV & 238 & 96 & 110 & 95 & 171 & 268 \\
\hline $\begin{array}{l}\text { Poloidal distance from launch } \\
\text { point (standard deviation), } \mathrm{mm}\end{array}$ & 70 & 2.0 & 1.1 & 1.7 & 4.7 & 7.9 \\
\hline $\begin{array}{l}\text { Redeposition fraction (for } 5 \mathrm{~cm} \\
\text { near-surface-cutoff) }\end{array}$ & $0.950^{d}$ & 1.000 & 1.000 & 1.000 & 1.000 & 1.000 \\
\hline
\end{tabular}

a Except where noted denotes average value for redeposited ions

b Normal to surface

c Includes effect of high reflected Li component

$\mathrm{d}$ Total redeposition (with sol transport) $=0.998$ 